\title{
How is the Gamification of Syllabus Changes Courses Student's Perception Towards Lesson (Preeliminary Research)
}

\author{
Fitri Rofiyarti ${ }^{1}$, Muchamad Arif $^{2}$, Sugito Muzaqi ${ }^{3}$, Anisa Yunita ${ }^{4}$ \\ \{fitri.rofiyarti@narotama.ac.id $\left.{ }^{1}\right\}$ \\ 1,2,3,4 Narotama University
}

\begin{abstract}
The easiness and massive flow of information in this disruptive era bring great challenges to the world of education. The problems that arise are no longer about the search for learning information sources, but in the behavioral aspects. The existence of a higher tendency to experience boredom brings great demands for teachers to apply the right learning methods. One form of effort that can be done to overcome this problem is by performing gamification. In this study, the authors identified instructional design in the course syllabus and lecture contracts to change the students' perceptions of the courses that will be undertaken. The result of this gamification method is positively correlated with the motivation of students to take lectures comprehensively.
\end{abstract}

Keywords: word, gamification, perception, method

\section{The Importance of First Impression in the First Meeting}

The first meeting in one learning period (in one semester) brings important role in shaping students' perceptions of courses to be carried out. Conventionally, the first meeting is often filled with an explanation of the roadmap or syllabus on the topics to be discussed, the tasks that must be completed by students, and the rules that must be adhered to along with the consequences. Although initially made with the aim that the implementation of learning can be directed, packaging and delivery of the wrong learning plan can make students have a negative perception of the subject matter. In addition, another impact that occurs is feeling burdened especially for difficult subjects, the motivation to follow the course likely to decrease.

Another problem that also arises is that not infrequently the submission of this syllabus is only as a form of formality, the execution process is often far different from what is implemented. Evidently, from 15 teaching respondents only 4 teachers claimed that the syllabus that had been made and delivered to students could go according to plan. The rest claimed that the learning process was not in accordance with the syllabus and experienced changes almost reaching $40 \%$ of what was planned. In addition to the syllabus, lecture contracts that contain agreements between lecturers and students also have the same tendency, namely only at the level of formality. In terms of students, it turned out that not a few students considered that the 'tradition' 
of submitting syllabus to the first findings of the lectures that occurred in most higher education institutions was not so important that they decided not to attend the first meeting. There are several reasons that underlie these choices, namely (1) Mismatch syllabus with the implementation of learning (2) Ease to get syllabus independently (3) Feelings burdened with lecture topics, and (4) Feelings burdened with structured assignments. These reasons then have an impact on learning motivation which tends to be stagnant and even decrease the motivation of students to follow the overall course. Even though the first meeting of the lecture that was manifested through the syllabus and contract of the lecture was the starting point for the formation of perceptions whether further learning would be enjoyable. For that reason, in this study the authors made modifications to the syllabus and lecture contracts by using the gamification method to create a positive perception of the course.

\section{Gamification of Instructional Design}

The term gamification first appeared around the 2000s and began to get a lot of attention in 2010 [1]. "Enjoying Learning like Gaming" is the main principle in this concept. The word "game" itself have understanding of a game based on rules to achieve certain goals. The gamification approach traditionally refers to the process of reshaping social behavior in accordance with the prevailing system and reflected in games. Without doubt, games have high potential to motivate someone to do something. [2]The pleasure felt when playing has the task of creating a giant railroad. As known, significant problem faced by many schools is the lack of motivation and interest in learning. If given a choice, most will prefer to play games rather than reading or completing assignments.

Quoting the opinion of Sailer [3], gamification refers to the use of game building elements in the context of non-games such as education, marketing, health, environment, etc. The main idea is to use building blocks from games and implement them in real-world situations, often with the aim to motivate certain behaviors by understanding the situation. Gamification is considered a promising concept and is very innovative, besides the most important thing is that it can be applied in various contexts. There are several creative reasons used in education, as quoted from increasing student involvement and motivation (2) improving performance and academic performance (3) improving memory (4) giving instant feedback on student activities and progress (5) catalyzing behavior change (6) allows students to see progress independently (7) develops the ability to collaborate.

When talking about gamification, one of the questions that often arises is whether there is a difference between gamification and game-based learning. Keeler as cited in Alsawaier [4] explained that the big difference between the two, games-based learning is where students play games to learn content. On the other hand, gamification is a form of application of game elements in non-games situations. This argument also supported by Isaac, cited in Alsawaier [4] which clearly distinguishes the two approaches, "Gamification has been integrated in a more authentic manner as some classrooms have become a living breathing game .... . Unlike gamification, game-based learning relates to the use of games to enhance the learning experience".

The present study of gamification is intended limited to use terms in the game in the learning process, especially those manifested in syllabus and lecture contracts. The author makes changes to conventional terms to create a learning situation where students seem to be participating in a 
game in the real world. In other words, the writer does the gamification on instructions. This can be a way for students to achieve learning goals and make the learning process in the class fun.

Thus, the aim of gamification is to make instruction feel good and worth learning. Faghihi, quoted from Kibonggsong [5] stated "If the instruction was neither fun nor worth learning (relevant to the learner), the learners will be less motivated and lose interest in the next lesson. If the instruction was worth learning, but not fun, the learners cannot recognize any differences between the instruction using the gamification and traditional instruction." Faghini illustrates it in the following chart.

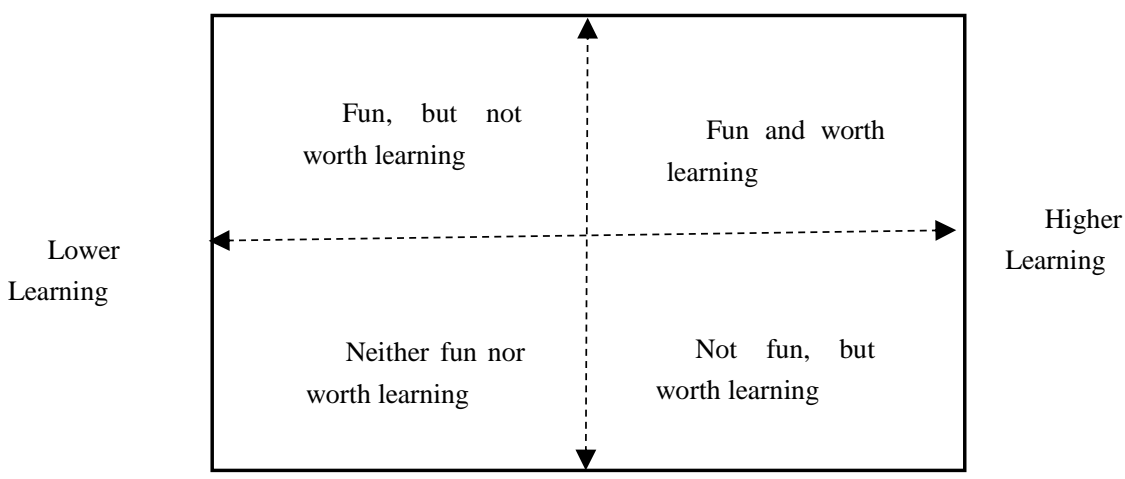

Fig. 1 Four results of instruction using gamification

In this study, the subjects chosen were European Studies and adapted the glossary of one of the most popular historical genre games, Age of Empires. This game was chosen because it has a theme that matches the subject. The following are some forms of instructional gamification performed.

Table 1. Gamification on elements of course syllabus

\begin{tabular}{ll}
\hline \multicolumn{1}{c}{ Syllabus component } & \multicolumn{1}{c}{ Gamification component } \\
\hline Syllabus & Book of Rules \\
Topics & Story \\
Learning Outcomes & Mission \\
Task & Challenges \\
Exam & Quest \\
Value & Level \\
Reading material & Treasure \\
\hline
\end{tabular}

As part of research and development $(\mathrm{RnD})$ research , the author uses mix-methods to determine the perceptions of students about the courses they will study in one semester. Quantitative and qualitative data were obtained from questionnaires and deep interviews with several students. Data collection was carried out after an explanation of the syllabus was given at the first meeting. 


\section{Gamification and The Power of Words}

The author sees that this gamification is one manifestation of the power of words. Only by changing terms with vocabulary that previously was positively correlated was it able to influence psychologically. Gressick [6]revealed, "There are many psychological underpinnings that support gamification as a widely applicable, effective approach to classroom pedagogy." The result, students prefer the terms of the term games rather than conventional terms that can be used even if the essence of the material to be taught is the same. Several reasons were stated, including (1) the existence of curiosity (2) the existence of a feeling of being challenged (3) the desire to be superior. Quoting from Brull [7] Werbach and Hunter explained, "Some gaming experts use the self-determination reason why gamification works in education. Self-determination theory is often associated with motivation and has three key elements, which include autonomy, competence, and relatedness. "

\section{Conclusion}

Gamification of the instructional design (syllabus and contract of the lecture) can provide a positive perception of the courses that will be undertaken. Gamification is indeed a complex concept, but starting to clarify the syllabus and lecture contracts can be one of the good first steps and interesting alternatives. Gamification in instructional design was able to bring a positive perception because they feel challenged, non burdened by tasks, increase the sense of curiosity, and a desire to be more superior to the other. Gamification is able to build positive competitive situations instantly.

\section{References}

[1] A. Pratomo, "Pengaruh Konsep Gamifikasi Terhadap Tingkat Engagement," vol. 8, no. 2, pp. 63-74, 2018.

[2] J. Woodcock and M. R. Johnson, "Gamification: What it is, and how to fight it," Sociol. Rev., vol. 66, no. 3, pp. 542-558, 2018.

[3] M. Sailer, J. U. Hense, S. K. Mayr, and H. Mandl, "How gamification motivates: An experimental study of the effects of specific game design elements on psychological need satisfaction," Comput. Human Behav., vol. 69, pp. 371-380, 2017.

[4] R. S. Alsawaier, "The effect of gamification on motivation and engagement," Int. J. Inf. Learn. Technol., vol. 35, no. 1, pp. 56-79, 2018.

[5] S. Kibonggsong and B. Johnnburton, Advances in Game-Based Learning Gamification in Learning and Education Enjoy Learning Like Gaming. .

[6] J. Gressick and J. B. Langston, "The Guilded Classroom: Using Gamification to Engage and Motivate Undergraduates," J. Scholarsh. Teach. Learn., vol. 17, no. 3, p. 109, 2017.

[7] S. Brull and S. Finlayson, "Importance of Gamification in Increasing Learning," J. Contin. Educ. Nurs., vol. 47, no. 8, pp. 372-375, 2016. 